\title{
Apresentação do Dossiê: Antropologia das Áreas Protegidas e da Sustentabilidade
}

Thiago Mota Cardoso, Ludivine Eloy, Henyo Trindade Barretto Filho e Pedro Castelo Branco Silveira

\section{(2) OpenEdition \\ 1 Journals}

Edição electrónica

URL: https://journals.openedition.org/aa/4926

DOI: $10.4000 /$ aa. 4926

ISSN: 2357-738X

Editora

Programa de Pós-Graduação em Antropologia Social (UnB)

\section{Edição impressa}

Paginação: 11-24

ISSN: 0102-4302

Refêrencia eletrónica

Thiago Mota Cardoso, Ludivine Eloy, Henyo Trindade Barretto Filho e Pedro Castelo Branco Silveira, «Apresentação do Dossiê: Antropologia das Áreas Protegidas e da Sustentabilidade», Anuário

Antropológico [Online], v.45 n. 1 | 2020, posto online no dia 27 janeiro 2020, consultado o 24 julho 2022. URL: http://journals.openedition.org/aa/4926 ; DOI: https://doi.org/10.4000/aa.4926

\section{(c) $)(9)$}

Creative Commons - Atribuição-NãoComercial-SemDerivações 4.0 Internacional - CC BY-NC-ND 4.0 https://creativecommons.org/licenses/by-nc-nd/4.0/ 


\section{Apresentação do Dossiê: Antropologia das Áreas Protegidas e da Sustentabilidade}

Presenting the Dossier: Anthropology of

Protected Areas and Sustentability

DOI: https://doi.org/10.4000/aa.4926

Henyo Trindade Barretto Filho - Universidade de Brasília - Brasil

ORCID: $\odot \odot 0 \odot-0003-3845-9936$

Doutor em Antropologia Social (FFLCH/USP, 2001) e Professor Adjunto do Departamento de Antropologia da Universidade de Brasília, onde também colabora no Mestrado Profissional em Sustentabilidade junto a Povos e Terras Tradicionais do Centro de Desenvolvimento Sustentável.

\section{Ludivine Eloy • Universidade de Brasília - Brasil}

Engenheira Agrônoma e Doutora em Geografia pela Universidade de Paris III (Sorbonne Nouvelle). É pesquisadora do Centro Nacional de Pesquisa Cientifica (Montpellier, França) e Professora visitante no Centro de Desenvolvimento Sustentável da Universidade de Brasilia, DF.

Pedro Castelo Branco Silveira • Fundação Joaquim Nabuco - Brasil

Thiago Mota Cardoso - Universidade Federal da Bahia - Brasil

Pós-Doutorando na Universidade Federal da Bahia, Doutor em Antropologia Social pela Universidade Federal de Santa Catarina, com estágio no projeto AURA - Living in the Anthropocene, na Aarhus University. Mestrado em Ecologia pelo Instituto Nacional de Pesquisas da Amazônia. 


\section{Introdução}

Áreas protegidas, têm sido, ao longo do último meio século, estabelecidas por muitos países em diferentes biomas e correspondem, hoje, a uma das principais estratégias de conservação da biodiversidade in situ e de proteção dos territórios das sociedades tradicionais em todo o mundo e já abrangem cerca de $13 \%$ da superfície terrestre do planeta (Bensusan, 2006). Isso sugere que elas devem ter impactos socio-ecológicos de importância global e local e levantar questões relevantes para reflexão antropológica. A proposta deste dossiê temático é fruto da reflexão de seus organizadores em torno do tema da antropologia das áreas protegidas e da sustentabilidade, que resultou na realização do painel Anthropology of Protected Areas and Sustainability, durante o XVIII International Union of Anthropological and Ethnological Sciences World Congress, realizado em Florianópolis em agosto de 2018.

O painel teve como objetivo entrelaçar pesquisadores e pesquisas antropológicas que se desafiam a construir um entendimento etnograficamente inspirado em torno do debate da sustentabilidade - em particular, abordagens contemporâneas sobre os espaços territoriais especialmente protegidos: as unidades de conservação da natureza, as terras tradicionalmente ocupadas por indígenas e quilombolas, dentre outros povos e comunidades. Compreendemos que a antropologia pode e deve continuar a ter um papel central nos debates e atuações em conexões locais e globais sobre ambiente, ambientalismo e desenvolvimento sustentável, se debruçando sobre territórios destinados à proteção especial do Estado ou protegidos pelos povos e comunidades tradicionais, com fins de perpetuar diversos modos de existências.

Isto implica, como buscam provocativamente os artigos do dossiê, o desafio às noções que sustentam as ideias de natureza e de humanidade que dão ancoragem ao conceito de sustentabilidade, bem como um olhar mais detido sobre os modos como territórios protegidos são criados e perpetuados.

\section{Antropologia, sustentabilidade e as áreas protegidas}

O tema da sustentabilidade (Brightman; Lewis, 2017; Escobar, 2011; Haenn; Wilk, 2006; Murphy; McDonagh, 2016; Persoon; Van Est, 2000; Redclift, 2002) e das áreas protegidas (Aubertin; Rodary, 2011; Barretto Filho, 2004; Diegues, 1996; Guha, 1989; West; Brockington, 2006; West et al., 2006) ganhou grande atenção de antropólogos e outros cientistas sociais nos anos 1990 e na primeira década do ano 2000. Em boa parte, tal atenção se deu devido à emergência dos movimentos socioambientalistas e da ambientalização (ver Latour et al., 1988; Lopes, 2006) das questões sociais entre os povos indígenas e comunidades locais que enfrentavam projetos de desenvolvimento e se deparavam com iniciativas conservacionistas que afetavam seus territórios e modos de vida, como as áreas protegidas (Diegues, 1996; Eloy et al., 2016; Guha; Alier, 2013; Little, 1999, 2002; Milton, 2013; Neumann, 1998; Ribeiro, 1991). Agora, com o avanço da chamada crise climática e do aquecimento global (Crate; Nuttal, 2016), tais olhares da antropologia para a questão das áreas protegidas como via para a sustentabilidade ganham novos e inusitados contornos. 
Os primeiros estudos em torno do tema das áreas protegidas na antropologia tinham como foco os debates a respeito dos impactos dos projetos de desenvolvimento econômico e do ambientalismo sobre populações locais (Albert, 2004; Fisher, 1994), com olhares mais detidos sobre os conflitos entre atores sociais na criação e implantação de áreas protegidas para conservação da natureza (Amend; Amend, 1995; Anderson; Grove, 1989; Creado, 2011; Diegues, 1996, 2000; Diegues; Nogara, 1999; Ferreira et al., 2001; Ghimire; Pimbert, 2013; Mendes et al., 2005; Ricardo, 2004; Shepard et al.,2010; Silveira, 2010; West et al., 2006;). As reflexões em torno do chamado conflito entre parques e pessoas engendraram novas agendas de pesquisa, como sobre as possibilidades e experiências de conservação com viés socioambiental e sobre o surgimento da categoria povos (comunidades, ou populações) tradicionais como protagonistas ou como vítimas da conservação ambiental. Destacamos aqui a emergência do socioambientalismo como uma dimensão inovadora no Brasil, que decorre de um amplo conjunto de pesquisas interdisciplinares engajadas, resultantes de redes de relações transescalares entre acadêmicos, movimentos sociais, organizações não governamentais e diferentes instâncias de governo - entre outros fatores (Almeida, 2004; Almeida; Rezende, 2013; Barreto Filho, 2006; Carneiro da Cunha; Almeida, 2000; Creado et al., 2008; Diegues, 2000; Santilli, 2005.).

Mais recentemente, os estudos antropológicos sobre as áreas protegidas e sustentabilidade se estenderam para a compreensão das diversas formas de manejo etnoecológico, conhecimentos tradicionais e transformação da paisagem e da biodiversidade (Balee, 1989; Posey; Balick, 2006; Orlove; Brush, 1996; Carneiro da Cunha; Almeida, 2002; Clement, 2015; Toledo; Barrera-Bassols, 2015; Borges et al.,2016; Lucio et al., 2016), o desenvolvimento de políticas públicas e instrumentos de gestão participativa de áreas protegidas (Kothari, 1996; Pimbert; Pretty, 1997; Brosius et al., 2005; Mendes et al., 2006; Illenseer; Cardoso, 2011), formas locais de percepção e cuidado com o ambiente (Colchester, 1996; Diegues, 2000; Cardoso, 2018), tensões em torno do conceito de sustentabilidade e habitabilidade (Tsing, 2019; Kothari, 2008), ecologia política e governabilidade (Escobar, 1998; Agrawal, 2005; Cardoso et al., 2008; Ioris, 2014), diferentes concepções de natureza e cultura e os conflitos ontológicos em torno da sustentabilidade (Descola; Palsson, 2001 Posey; Balick, 2006; Maffi, 2007; Almeida, 2013; Green, 2013; Lima et al., 2018) e resiliência e gestão comunitária de territórios e ambientes (Diegues; Moreira, 2001; Brosius et al., 2005; Berkes et al., 2008). Destaca-se, nesse período, a produção de uma variedade de monografias de cunho etnográfico na Amazônia e Mata Atlântica, abordando situações em diversas contextos e, ao mesmo tempo, um interesse crescente por outros biomas (ou sistemas biogeográficos), como o Cerrado, a Caatinga, os Campos Sulinos e o Pampa, em trabalhos que cruzam Antropologia e Ecologia/Biologia - o que parece ser uma contribuição específica do campo científico brasileiro nesse tema.

As áreas protegidas eram compreendidas até então, nos marcos estritos da literatura normativa, como porções de um território protegidas institucionalmente para fins de conservação ambiental, belezas cênicas ou proteção do patrimônio 
cultural de uma nação. A União Internacional de Conservação da Natureza - IUCN define área protegida, num sentido mais estrito, como o espaço geográfico claramente definido, reconhecido, com objetivo específico e gerido por meios eficazes, sejam jurídicos ou de outra natureza, para alcançar a conservação da natureza no longo prazo, com serviços ecossistêmicos e valores culturais associados (Dudley, 2008, p. 10) ${ }^{1}$. No Brasil, o termo áreas protegidas corresponderia a um espaço regulamentado que, segundo a Constituição Federal de 1988, iria além dos objetivos de proteção ambiental, abarcando todos os espaços territoriais e seus componentes a serem especialmente protegidos (Bensusan, 2008). Recentemente, além das unidades de conservação, na esteira da ambientalização das lutas sociais, as terras indígenas, quilombos e outros territórios tradicionalmente ocupados vêm sendo tratados, pelo poder público e por grande parte da sociedade civil organizada, como territórios que incluem, além das garantias de direitos étnicos e culturais, a conservação da biodiversidade e o desenvolvimento sustentável. $\mathrm{Na}$ Política Nacional das Áreas Protegidas - PNAP, já podemos observar tal esforço de tornar mais elástico o conceito de áreas protegidas, sendo o mesmo definido da seguinte forma:

áreas naturais e semi-naturais definidas geograficamente, regulamentadas, administradas e/ou manejadas com objetivos de conservação e uso sustentável da biodiversidade. Enfoca prioritariamente o Sistema Nacional de Unidade de Conservação, as terras indígenas e os territórios quilombolas. Sendo que as demais áreas protegidas, como as áreas de preservação permanente e as reservas legais são tratadas no planejamento da paisagem, no âmbito da abordagem ecossistêmica, com uma função estratégica de conectividade entre fragmentos naturais e as próprias áreas protegidas (Brasil, 2006).

Atualmente, as áreas protegidas enfrentam dificuldades de institucionalização, agravadas pela perda de visibilidade pública das questões ambientais e fundiárias, ataques às legislações referentes ao meio ambiente, aos povos indígenas, às comunidades quilombolas e às comunidades tradicionais. Mais do que isso, o Brasil dos últimos anos foi marcado por verdadeiras catástrofes ambientais, como a construção da Usina de Belo Monte e o rompimento da barragem de rejeitos de mineração da Vale em Mariana, além da expansão do agronegócio e do desmatamento, da escalada de assassinatos a lideranças ambientalistas e de outros movimentos sociais. Nesta esteira, áreas protegidas passam a ser invadidas por agentes econômicos e ameaçadas por diversos projetos legislativos que visam diminuir seus tamanhos ou simplesmente cancelar sua criação. Paralelo a isto, observamos territórios e lugares sagrados, protegidos pelos povos indígenas, ameaçados e impactados por projetos de desenvolvimento de larga escala.

Este dossiê visa destacar a necessidade de uma compreensão mais sistemática das áreas protegidas e trazer à tona abordagens contemporâneas sobre o tema no Brasil e outros locais da América Latina, inspiradas em uma multiplicidade
1 No Brasil é utilizado o termo unidade de conservação (UCS) para diferenciar territórios especialmente destinados à conservação da biodiversidade de outras áreas protegidas. 0 Sistema Nacional de Unidades de Conservação - SNUC determina duas categorias de Ucs, as de Proteção Integral e as de Uso Sustentável. As UCs de Proteção Integral são as que não permitem o uso direto da biodiversidade e do espaço por populações humanas, salvo para atividades de pesquisa e recreativas previstas nos planos de manejo e zoneamentos. Já as Ucs de Uso Sustentável pressupõem o uso parcimonioso por populações humanas, incluindo povos e comunidades tradicionais (Bensusan, 2006). 
de abordagens etnográficas. Aportes antropológicos aos ambientalismos (idéias sobre como devemos habitar o ambiente) e à conservação (práticas de uso ou não de natureza) estão produzindo teorias e abordagens etnográficas variadas, interagindo com perspectivas emergentes dos povos indígenas, comunidades tradicionais e camponeses, evidenciando práticas e relações de poder na criação e implementação de áreas protegidas, conflitos socioambientais e as dimensões ontológicas e epistemológicas que os cercam.

Ao mesmo tempo, os artigos do Dossiê seguem uma compreensão que tem se generalizado sobre a importância de territórios tradicionais, reconhecidos ou não pelo Estado, na manutenção da biodiversidade e da sociodiversidade por meio de suas próprias formulações sobre o ambiente, sobre habitabilidade e proteção dos diversos modos de vida. Aqui compreendemos áreas protegidas não apenas como modos estatais de constituição de seus territórios a partir do ordenamento público, mas também como modos outros de realizar a proteção de lugares e paisagens, como os lugares sagrados, as áreas restritas, os territórios pesqueiros e as experiências agroecológicas. Assim, proteger pode ser entendido aqui não apenas no sentido estatal de interditar ou controlar, mas também como o que Isabelle Stengers (2015) chama a arte de ter cuidado.

\section{A arte de ter cuidado, etnografias das e nas áreas protegidas}

No campo dos estudos antropológicos sobre áreas protegidas no Brasil, destacamos em sua gênese os estudos etnográficos e reflexões sobre os impactos sociais da criação das áreas protegidas e os conflitos derivados de sua implementação num viés denominado de cercas e multas. Tais estudos eram focados em desvelar as injustiças sociais durante a criação das áreas protegidas, bem como os processos de desterritorialização e remoção de famílias de seus lugares e moradias, impedimentos de acesso aos ambientes e organismos animais e vegetais, e a repressão de comunidades locais por agentes fiscalizatórios, mapeavam os atores sociais envolvidos nos conflitos, suas perspectivas nas arenas públicas e seus modos de resistência e enfrentamento. Ao mesmo tempo, muitos trabalhos enfrentavam tais situações ao se debruçar nas diferentes e conflitantes formas de apropriação da terra e dos recursos naturais entre Estados Nacionais e comunidades locais, bem como nas diferentes bases epistemológicas e cosmológicas que sustentavam diferentes concepções de natureza e cultura (ver Almeida; Rezende, 2013; Barretto F 2004, 2006; Creado, 2008; Diegues, 1996; Diegues; Nogara, 1999; Ioris, 2014; Little, 2002; Mendes, 2005; Ricardo, 2004; Shepard et al., 2010; Vianna, 2008).

O trabalho de Natália Guerrero, Em termos alheios: Contradições da implementação de termos de compromisso em territórios tradicionalmente ocupados, dá continuidade a esta agenda de pesquisa ao se debruçar sobre a ambiguidade dos instrumentos criados pelo Estado, como os Termos de Compromisso, para gerir ou mitigar os conflitos oriundos da criação de áreas protegidas na Amazônia brasileira. A partir da análise etnográfica da implementação de um instrumento de gestão de conflitos, a autora adentra nas contradições da política ambiental brasileira em torno do debate sobre as Unidades de Conservação e Povos e Co- 
munidades Tradicionais e Sobreposições Territoriais, um tema/problema que opõe diversos lados na academia e na sociedade civil organizada (Ricardo, 2004): enquanto as vertentes preservacionistas defendem as retiradas de populações humanas de dentro das áreas protegidas, as socioambientalistas argumentam pela possibilidade de convivência entre humanos e seus ambientes. Seu trabalho etnográfico trata da interdição às terras tradicionalmente ocupadas por beiradeiros do rio Xingu e Iriri, na Terra do Meio, após a criação de um mosaico de áreas protegidas na região com fins de mitigar o avanço dos desmatamentos, bem como as formas de resistência cotidiana dos habitantes de uma área de proteção integral.

$\mathrm{O}$ artigo Construindo aldeias e recuperando matas, de Renan Pinna, também se debruça sobre o tema da sobreposição entre unidades de conservação de proteção integral e terras indígenas, e sobre as lutas etnopolíticas dos Avá Guarani do Paraná para recuperar seu território ancestral. Pinna nos brinda com uma etnografia de um conflito territorial que opõe perspectivas cosmológicas diferentes sobre natureza, questionando uma pergunta recorrente entre os socioambientalistas: seriam os povos tradicionais conservacionistas?2 ${ }^{2}$ Para o autor, a noção de conservação estaria amparada em modelos estrangeiros aos povos indígenas, o que na prática os vem impedindo de habitarem as suas terras tradicionais. Por outro lado, aponta que as elaborações cosmológicas dos Avá Guarani estão conectadas a uma conotação de ética de conservação, que os leva a empreender nas retomadas de terras um projeto de recuperação ambiental que segue a lógica do guata porã, das boas caminhadas, das caminhadas sagradas, amparados pela busca de um teko porã (terra boa) para habitar.

São cada vez mais recorrentes e bem-vindos estudos antropológicos como o de Renan Pinna, que buscam compreender os modos como os povos indígenas e comunidades locais convivem com outras vidas em seus territórios. Inspirados por este caminho, Lara Erendira Almeida de Andrade e Marcelino Soyinka Santos Dantas realizaram uma pesquisa inédita sobre o papel das terras indígenas para a manutenção da sociobiodiversidade no semiárido nordestino. Cabe registrar, como fazem os autores, que os territórios indígenas situados na Caatinga tiveram pouca, para não dizer nenhuma, visibilidade no debate ambiental ainda sob forte influência do mito moderno da natureza intocada (ver Diegues, 1996) e de certas Antropologia e Ecologia tropicais focalizadas historicamente nas florestas tropicais úmidas. A prevalência desse mito e da negligência em torno do tema ambiental entre os povos indígenas no Nordeste reverbera na forma em que se associa a imagem destes povos, vistos como índios misturados e impuros, que habitariam uma natureza já modificada, portanto de menor valor para a conservação.

Por meio de uma reflexão em torno da realização de etnomapeamentos da paisagem junto aos povos Xokó (SE), Pankararu e Kapinawá (PE), como parte de um processo de gestão ambiental e territorial das terras indígenas brasileiras, os autores desafiam o discurso institucional que minoriza os povos indígenas que habitam a Caatinga. No texto e nos mapas das Terras Indígenas, os autores nos brindam com convincentes descrições de que, mesmo com a escassez de iniciativas estatais e não estatais de apoio aos direitos dos povos indígenas e de conservação
2 Pergunta similar já vinha sendo feita em termos tanto gerais quanto específicos, para comunidades e povos tradicionais peculiares - como no caso da pioneira tese de doutorado de Adams sobre caiçaras da Mata Atlântica de 1996 (depois publicada em livro - Adams, 2000). Para além desse debate sobre a intencionalidade conservacionista ou não desses modos de vida, já há algum tempo está estabelecido para a Amazônia que as TIs são instrumentos até mais eficazes que as UCs na contenção ao desmatamento na Amazônia, bem assim como outras áreas protegidas e habitadas por povos tradicionais. Ferreira et al. (2005) já haviam demonstrado, há quase duas décadas, que o desmatamento era cerca de dez a vinte vezes menor, respectivamente, dentro das UCs e TIs do que em áreas contíguas fora delas. A importância dessas áreas protegidas para diminuir o processo do desmatamento foi posteriormente confirmada por Ricketts et al. (2010) - embora isso não deixe de nos colocar novas perguntas para a análise. 
ambiental, seus territórios podem ser vistos como responsáveis por conservação da biodiversidade no contexto do Semiárido brasileiro.

$\mathrm{O}$ argumento que busca tratar terras indígenas como áreas protegidas também permeia o artigo Awnetypan amazad: politicas indigenas do habitar e gestão territorial-ambiental em terras indigenas, de Alessandro Roberto de Oliveira. Oliveira nos oferece uma análise etnográfica acerca das políticas do habitar (Ingold, 2005) que operam entre o povo Wapichana de Roraima durante a elaboração de um Plano de Gestão Ambiental e Territorial (PGTA). Nesse texto etnográfico sensível, modos específicos de relações com lugares, ecologias da vida e as formas próprias de habitar dos Wapichana são evidenciadas em entrelaçamento e tensão intercultural com a agenda de uma política pública de gestão territorial e ambiental de terras indígenas no Brasil.

Segundo Oliveira, é possível encontrar ressonâncias entre as concepções próprias de relações dessas sociedades com o que se convencionou chamar de seus territórios e ambiente, e a agenda de gestão territorial e ambiental de terras indígenas. $\mathrm{O}$ autor, porém, chama atenção para o fato de que tais conexões não desfazem diferenças cosmológicas e políticas importantes: são marcadas por mal-entendidos, equívocos, contradições e assimetrias de poder que caracterizam historicamente as relações interétnicas no campo das políticas públicas ambientais formuladas para as terras indígenas, que se assentam em regime modernista, com predomínio do dualismo entre natureza e cultura, e da incorporação progressiva da natureza ao domínio da governamentalidade e do mercado. Por sua vez, os Wapichana desenvolvem em seu cotidiano um modo de habitar caracterizado por cuidar da terra, ou awnetypan amazad, em sua língua.

Continuando na Amazônia e também se defrontando com diferentes (e muitas vezes divergentes) cosmologias sobre a terra, ambiente e sustentabilidade, Roberto Rezende apresenta uma análise do instrumento de Pagamentos por Serviços Ambientais junto aos habitantes das reservas extrativistas (Resex) Rio Iriri, Riozinho do Anfrísio e Rio Xingu na Terra do Meio, no Pará, apontando para as contribuições dos povos e comunidades locais que habitam tais áreas protegidas para o manejo da biodiversidade e a regulação do clima. $\mathrm{O}$ artigo apresenta um processo em curso de identificação das contribuições dos extrativistas e agricultores, habitantes da Terra do Meio, problematizando a participação comunitária nos sistemas de pagamentos por serviços ambientais ou por serviços ecossistêmicos (Eloy et al., 2013; Eloy et al., 2012) nos quadros do reconhecimento crescente da contribuição dos povos tradicionais para a sociobiodiversidade e o combate às mudanças climáticas.

Ao longo do texto, o autor tece considerações sobre as limitações de mecanismos de mercado para promover os serviços socioambientais que estão intimamente ligados às formas tradicionais de manejo. Ao mesmo tempo e seguindo o argumento de autoras como Manuela Carneiro da Cunha (2010), aponta que a questão central nos chamados projetos socioambientais não seria o foco em elementos isolados da natureza, mas sim um olhar detido na continuidade das práticas que reproduzem florestas diversificadas. Para Rezende, a questão da valoração 
dos serviços socioambientais e sua lógica de mercado coloca em jogo diferentes valores e interesses, podendo resultar em conflitos ontológicos.

Em Espacios Costeros Marinos Para Pueblos Originarios: usos consuetudinarios y conservación marina, Francisco Araos e colaboradores apresentam os resultados de uma pesquisa que trata do tema dos territórios comunais dos pescadores da região de Los Lagos no Chile e as interfaces entre os modos de gestão comunitários e os direitos estatais de regulação das zonas costeiras. $\mathrm{O}$ artigo trata das implicações analíticas e políticas do emprego do conceito de usos consuetudinários na aplicação do instrumento Espacios Costeros Marinos para Pueblos Originarios (ECMPOs), como modo de gestão e delimitação de zonas marinhas pelo poder público, cujo objetivo primordial é o resguardo dos usos costumeiros praticados por comunidades indígenas da zona costeira chilena. Araos e colaboradores argumentam que o estabelecimento dos ECMPOs vem desencadeando transformações nos usos diversos dos recursos marinhos e invisibilizando as estratégias locais frente ao modo de regulação estatal. Todavia, e ao mesmo tempo, são parte das multiplas estratégias indígenas de enfrentar o despojo del mar, os regimes de propriedade e de privatização dos recursos e espaços comuns.

Enfrentando também o tema da privatização dos espaços comuns e as áreas protegidas, porém com uma diferente proposta teórico-metodologica, Pedro Silveira e Rafael Buti se colocaram o desafio de realizar uma etnografia dos limites de um projeto colaborativo voltado para a compreensão da ecologia política dos crustáceos nos manguezais em um Quilombo e uma Reserva Extrativista do Nordeste.

Em A vida e a morte dos guaiamuns: antropologia nos limites dos manguezais, os autores exploram as relações que envolvem a coexistência dos caranguejos conhecidos como guaiamuns (Cardisoma guanhumi) com os grupos humanos que os capturam em manguezais de Pernambuco e Bahia. Munidos de uma criativa e original proposta etnográfica, descrevem as fricções na produção de paisagens multiespécies de manguezal, sobretudo as em tensão histórica com os empreendimentos industriais e agroindustriais poluidores, bem como com os modos estatais de controle e gestão marinha. A análise, segundo os autores, posiciona a pesca de guaiamuns em uma diversidade de situações caracterizadas pela noção de limite.

Embora quase todos os artigos abordem a contribuição de povos indígenas e comunidades tradicionais para a manutenção e até a geração da sociobiodiversidade, alguns alertando sobre a dificuldade de contemplar os conhecimentos de tais povos nos arranjos de PSA (associados à mercantilização da natureza), eles não se baseiam em pesquisas por definição colaborativas sobre esses temas - tais como Cabalzar (2010) e as dissertações de mestrado de alunos indígenas, quilombolas e de comunidades tradicionais defendidas no âmbito do Mestrado em Sustentabilidade junto a Povos e Territórios Tradicionais da Universidade de Brasília (alguns dos quais têm nos feito avançar no debate sobre a articulação entre regimes de conhecimento). Parte dessa literatura vem sendo produzida por instituições não acadêmicas no âmbito de esforços de diálogo intercultural guiados por uma sensibilidade antropológica e etnográfica, que, justamente, tentam transcender a grande divisão natureza/cultura e reduzir a assimetria entre regimes de conhecimentos 
na apreciação de todos esses temas. Não sendo esse o foco do dossiê, destacamos que o leitor tem em mãos um conjunto de artigos resultantes de pesquisas e reflexões que tratam da proliferação de encontros entre a questão ambiental e povos indígenas e comunidades tradicionais em diversas situações etnográficas, sobre manejo e recuperação da biodiversidade e das paisagens, a espacialização das ações de conservação, a produção de conhecimentos sobre a gestão de áreas protegidas e as ligações entre aquecimento global e áreas protegidas.

Recebido: $12 / 11 / 2019$

Aprovado: 18/11/2019 


\section{Referências}

ADAMS, Cristina. Caiçaras na Mata Atlântica: pesquisa científica versus planejamento e gestão ambiental. São Paulo: Annablume; Fapesp, 2000.

AGRAWAL, Arun. Environmentality: technologies of government and the making of subjects. Durham, N.C., USA: Duke University Press, 2005.

ALBERT, Bruce. 2004. Territorialidad, etnopolítica y desarrollo: a propósito del movimiento indígena en la Amazonia brasileña. In: SURRALLÉS, A.; GARCÍA HIERRO, P. (Eds.). Tierra adentro. Territorio indígena y percepción del entorno. Lima: Grupo Internacional de Trabajo sobre Asuntos Indígenas (IWGIA) , 2004. p. 221-258.

ALMEIDA, Mauro William Barbosa de. Caipora e outros conflitos ontológicos. RAU, v. 5, $\mathrm{n}$. 1, p. 7-28, 2013.

ALMEIDA, Mauro W. et al. Direitos à floresta e ambientalismo: seringueiros e suas lutas. Revista Brasileira de Ciências Sociais, v. 19, n. 55, p. 33-52, 2013.

ALMEIDA, Mauro W. Barbosa; REZENDE, Roberto. Uma nota sobre comunidades tradicionais e unidades de conservação. RURIS - Revista do Centro de Estudos Rurais, v. 7, n. 2, p. 185-196, 2013.

AMEND, Stephan; AMEND, Thora. 1995. Espacios sin habitantes? Parques nacionales de América del Sur. National parks without people? The South American experience. Quito (Ecuador): The International Union for Conservation of Nature - IUCN, Gland (Suiza) Parques Nacionales y Conservación Ambiental,1995.

ANDERSON, David; GROVE, Richard (Eds). Conservation in Africa: peoples, policies and practice. Cambridge: Cambridge University Press, 1989.

AUBERTIN, Catherine; ESTIENNE, Rodary (Eds.). Protected Areas, Sustainable Land? Surrey, England: Ashgate Press, 2011.

BALÉE, William. 1989. The culture of Amazonian forests. Advances in economic botany, v. 7, n. 1, 1989.

BARRETTO FILHO, Henyo Trindade. 2004. Notas para uma história social das áreas de proteção integral no Brasil. In: RICARDO, Fany (Org.). Terras Indígenas e Unidades de Conservação da natureza: o desafio das sobreposições. São Paulo: Instituto Socioambiental, 2004

BARRETTO FILHO, Henyo Trindade. Populações tradicionais: introdução à crítica da ecologia política de uma noção. In: ADAMS, Cristina; MURRIETA, Rui; NEVES, Walter (Eds.). Sociedades caboclas amazônicas: modernidade e invisibilidade. São Paulo: Annablume, 2006.

BENSUSAN, Nurit. Conservação da biodiversidade em áreas protegidas. Rio de Janeiro: FGV Editora, 2006.

BORGES, Sílvia Laine et al. Fire management in veredas (palm swamps): new perspectives on traditional farming systems in Jalapão, Brazil. Ambiente \& Sociedade, v. 19, n. 3, p. 269-294, 2016.

BRASIL. Plano Estratégico Nacional de Áreas Protegidas - PNAP - Decreto $n^{\circ}$ 5.758, de 13 de abril de 2006. Brasília: Ministério do Meio Ambiente, 2006.

BRIGHTMAN, Marc; LEWIS, Jerome (Eds.). The anthropology of sustainability: beyond development and progress. Springer, 2017.

BROSIUS, Peter J.; TSING, Anna Lowenhaupt; ZERNER, Charles (Ed.). Communities and conservation: histories and politics of community-based natural resource manage- 
Henyo Trindade Barretto Filho, Ludivine Eloy, Pedro Castelo Branco Silveira, Thiago Mota Cardoso

ment. Rowman Altamira, 2005.

BERKES, Fikret; COLDING, Johan; FOLKE, Carl (Eds.). Navigating social-ecological systems: building resilience for complexity and change. Cambridge University Press, 2008.

CABALZAR, Aloisio (Org.). 2010. Manejo do Mundo: conhecimentos e práticas dos povos indígenas do Rio Negro, Noroeste Amazônico. São Paulo: ISA; São Gabriel da Cachoeira: FOIRN, 2010.

CARDOSO, Thiago Mota. Paisagens em transe: ecologia da vida e cosmopolítica Pataxó no Monte Pascoal. Brasília: IEB Mil Folhas, 2018.

CARDOSO, T. M. ; KURIHARA, L. P. ; MOSQUEIRA, F. ; SEMEGHINI, M. G. Povos Tradicionais e o ordenamento territorial na perspectiva da conservação e uso sustentável da biodiversidade no baixo Rio Negro. In: BENSUSAN, Nurit; ARMSTRONG, Gordon (Orgs.). Do manejo da paisagem a paisagem do manejo. Brasilia: IIEB, 2018.

CARNEIRO DA CUNHA, Manuela; ALMEIDA, Mauro W. B. Indigenous people, traditional people, and conservation in the Amazon. Daedalus, v. 129, n. 2, p. 315-338, 2000.

CARNEIRO DA CUNHA, Manuela; ALMEIDA, Mauro Barbosa de (Orgs.). Enciclopédia da Floresta: o Alto Juruá: práticas e conhecimentos das populações. São Paulo: Cia. das Letras, 2002.

CARNEIRO DA CUNHA, Manuela Carneiro da. Questões suscitadas pelo conhecimento tradicional. Revista de Antropologia, v. 55, n. 1, p. 439-464, 2012.

CLEMENT, Charles. et al. The domestication of Amazonia before European conquest. Proceedings of the Royal Society B: Biological Sciences, v. 282, n. 1812, 2015.

COLCHESTER, Marcus. Beyond "participation": indigenous peoples, biological diversity conservation and protected area management. UNASYLVA-FAO, n. 186, v. 47, p. 33-39, 1996.

COLEMAN, James S. The foundations of Social Theory. Cambridge: Harvard University Press, 1990.

CRATE, Susan A.; NUTTALL, Mark (Ed.). Anthropology and climate change: from encounters to actions. London: Routledge, 2016.

CREADO, Eliana Santo Junqueira et al. Entre tradicionais e modernos: negociações de direitos em duas unidades de conservação da Amazônia brasileira. Ambiente \& Sociedade, Campinas, v. XI, n. 2, p. 255-271, jul.-dez. 2008.

CREADO, Eliana Santos Junqueira. Lugares de vida, espaços de lembrança: conflitos e restrições socioambientais no Parque Nacional do Jaú (AM). São Paulo: Annablume, 2011.

DIEGUES, Antonio Carlos Sant'Ana (Org.). Etnoconservação: novos rumos para a proteção da natureza nos trópicos. São Paulo: Hucitec, 2000.

DIEGUES, Antonio Carlos Sant'Ana; NOGARA, Paulo José. O nosso lugar virou parque: estudo sócio-ambiental do Saco do Mamanguá, Paraty, Rio de Janeiro. São Paulo: USP/NUPAUB, 1999.

DIEGUES, Antonio Carlos Sant'Ana. Mito moderno da natureza intocada. São Paulo: Hucitec, 1996.

DIEGUES, Antonio Carlos Sant'Ana; MOREIRA, André de Castro (Org.). Espaços e recursos naturais de uso comum. São Paulo: Nupaub, 2001.

DUDLEY, Nigel. Directrices para la aplicación de las categorías de gestión de áreas protegidas. Gland, Suiza: UICN, 2008.

ELOY, L.; AUBERTIN, C.; TONI, F.; LÚCIO, S. L. B.; BOSIGIRAUD, M. On the margins of soy farms: traditional populations and selective environmental policies in the Brazilian 
Henyo Trindade Barretto Filho, Ludivine Eloy, Pedro Castelo Branco Silveira, Thiago Mota Cardoso

Cerrado. The Journal of Peasant Studies, n. 43, p. 494-516, 2016.

ELOY, Ludivine; COUDEL, Emilie; TONI, Fabiano. 2013. Implementando Pagamentos por Serviços Ambientais no Brasil: caminhos para uma reflexão crítica. Sustentabilidade em Debate, v. 4, n. 1, p. 21-41, 2013.

ELOY, L., MÉRAL, P., LUDEWINGS, T., PINHEIRO, G., SINGER, B. Payments for Ecosystem Services in Amazonia. The challenge of land use heterogeneity in agricultural frontiers near Cruzeiro do Sul (Acre, Brazil). Journal of Environmental Planning and Management, n. 55, p. 685-703, 2012.

ESCOBAR, Arturo. 2011. Sustainability: design for the pluriverse. Development, v. 54, n. 2, p. 137-140, 2011.

ESCOBAR, Arturo. Whose knowledge, whose nature? Biodiversity, conservation, and the political ecology of social movements. Journal of Political Ecology, v. 5, n. 1, p. 53-82, 1998.

FERREIRA, Leandro Valle; VENTICINQUE, Eduardo; ALMEIDA, Samuel. O desmatamento na Amazônia e a importância das áreas protegidas. Estudos Avançados, v. 19, n. 53, p. 157-166, 2005.

FERREIRA, Lúcia C. et al. Conflitos sociais em áreas protegidas no Brasil: moradores, instituições e ONGs no Vale do Ribeira e Litoral Sul, SP. Idéias, São Paulo, , v. 8, n. 2, p. 115-149, 2002.

FISHER, William H. Megadevelopment, environmentalism, and resistance: The institutional context of Kayapó indigenous politics in central Brazil. Human Organization, p. 220-232, 1994.

GHIMIRE, Krishna B.; PIMBERT, Michael P. Social change and conservation. London: Routledge, 2013.

GREEN, Lesley (Ed.). Contested ecologies: dialogues in the South on nature and knowledge. HSRC Press, 2013.

GUHA, Ramachandra. Radical American environmentalism and wilderness preservation: a third world critique. Environmental ethics, v. 11, n. 1, p. 71-83, 1989.

GUHA, Ramachandra; ALIER, Joan Martínez. Varieties of environmentalism: essays North and South. London: Routledge, 2013.

HAENN, Nora; WILK, Richard (Eds.). 2006. The environment in anthropology: a reader in ecology, culture, and sustainable living. New York; London: NYU Press, 2006.

ILLENSEER, Rafael; CARDOSO, Thiago. 2011. Mota. Mosaicos e povos indígenas: um ensaio sobre os povos Enawene Nawe e Deni e a temática da gestão territorial integrada. In: ARRUDA, Rinaldo S. V.; JAKUBASZKO, Andrea; RAMIRES, Marcos de M. (Orgs.). Reflexões indigenistas. Campinas, SP: Curt Nimuendajú, 2011.

IORIS, Edviges Marta. Uma floresta de disputas: conflitos sobre espaços, recursos e identidades sociais na Amazônia. Florianópolis: Editora da UFSC, 2014.

INGOLD, Tim. 2005. Epilogue: Towards a politics of dwelling. Conservation and Society, v. 3, n. 2, p. 501-508, 2005.

KOTHARI, Ashish. 2008. Protected areas and people: the future of the past. Parks, v. 17, n. 2, p. 23-34. 2008.

KOTHARI, Ashish. 2004. Protected areas and people: participatory conservation. Biodiversity issues for consideration in the planning, establishment and management of protected area sites and networks. Secretariat of the Convention on Biological Diversity, Biodiversity (SCBD) issues for consideration in the planning, establishment and 
management of protected area sites and networks. Montreal: SCBD, (CBD Technical Series no. 15).2004. (CBD Technical Series n. 15).

LATOUR, Bruno; SCHWARTZ, Cécile; CHARVOLIN, Florian. 1998. Crise dos meios ambientes: desafios às ciências humanas. In: ARAÚJO, Hermetes Reis de (Org.). Tecnociência e cultura: ensaios sobre o tempo presente. São Paulo: Estação Liberdade, 1998. p. 91-125.

LIMA, Ana. G. M. et al. 2018. Práticas e saberes sobre agrobiodiversidade: a contribuição de povos tradicionais. Brasilia: IEB Mil Folhas, 2018.

LITTLE, Paul Elliot. Environments and environmentalisms in anthropological research: facing a new millennium. Annual Review of Anthropology, v. 28, n. 1, p. 253-284, 1999.

LITTLE, Paul Elliot. Territórios sociais e povos tradicionais no Brasil: por uma antropologia da territorialidade. Brasília: DAN/UnB, 2002. (Série Antropologia nº 322).

LOPES, José Sérgio Leite. Sobre processos de "ambientalização" dos conflitos e sobre dilemas da participação. Horizontes Antropológicos, Porto Alegre, v. 12, n. 25, p. 31-64, 2006.

LÚCIO, Silvia Laine Borges; ELOY, Ludivine; SENA, Ana Carolina. As áreas protegidas e o manejo do fogo em sistemas agrícolas tradicionais no Jalapão (Brasil). Proceedings from the COMBIOSERVE Conference Community Conservation in Latin America: innovations in research and practice, Global Diversity Foundation, 2016.

MAFFI, Luisa et al. Biocultural diversity and sustainability. The SAGE Handbook of Environment and Society. London: SAGE Publications, 2007. p. 267-277.

MENDES, Ana Beatriz Vianna et al. Processos decisórios envolvendo populações que residem no Parque Nacional do Jaú (AM). III ENCONTRO DA ANPPAS, 23 a 26 de maio de 2006, Brasília-DF.

MILTON, Kay (Ed.). Environmentalism: the view from anthropology. London; New York: Psychology Press, 1993.

MURPHY, Fiona; MCDONAGH, Pierre (Eds.). Sustainabilities: towards an Anthropology of Sustainability. Cambridge: Cambridge Scholars Publishing, 2016.

NEUMANN, Roderick P. Imposing wilderness: struggles over livelihood and nature preservation in Africa. v. 4. California, USA: University of California Press, 1998.

ORLOVE, Benjamin S.; BRUSH, Stephen B. 1996. Anthropology and the conservation of biodiversity. Annual Review of Anthropology, v. 25, n. 1, p. 329-352, 1996.

PERSOON, Gerard A.; VAN EST, Diny M. E. The study of the future in anthropology in relation to the sustainability debate. Focaal, n. 35, p. 7-28, 2000.

PIMBERT, Michel P.; PRETTY, Jules N. Parks, people and professionals: putting "participation" into protected area management. Social change and conservation, n. 16, p. 297-330, 1997.

POSEY, Darrell Addison; BALICK, Michael J. (Eds.). Human impacts on Amazonia: the role of traditional ecological knowledge in conservation and development. Columbia University Press, 2006.

REDCLIFT, Michael. Sustainable Development: exploring the contradictions. London: Routledge, 2002.

RIBEIRO, Gustavo Lins. Ambientalismo e desenvolvimento sustentado. Nova ideologia/ utopia do desenvolvimento. Revista de Antropologia, FFLCH/USP, n. 34, p. 59-101, 1991.

RICARDO, Fany. Terras Indígenas e Unidades de Conservação da natureza: o desafio das 
Henyo Trindade Barretto Filho, Ludivine Eloy, Pedro Castelo Branco Silveira, Thiago Mota Cardoso

sobreposições. São Paulo: Instituto Socioambiental, 2004.

RICKETTS, T. H.; SOARES-FILHO, B. et al. Indigenous Lands, Protected Areas, and Slowing Climate Change. Plos Biology, v. 8, n. 3, 2010.

SANTILLI, Juliana. Socioambientalismo e novos direitos: proteção jurídica à diversidade biológica e cultural. São Paulo: Fundação Peirópolis, 2005.

SHEPARD JR, Glenn H. et al. 2010. Trouble in paradise: indigenous populations, anthropological policies, and biodiversity conservation in Manu National Park, Peru. Journal of Sustainable Forestry, v. 29, n. 2-4, p. 252-301, 2010.

SILVEIRA, Pedro Castelo Branco. Florestas e lutas por reconhecimento: território, identidades e direitos na Mata Atlântica brasileira. Campos-Revista de Antropologia, v. 11, n. 2, p. 95-112, 2010.

STENGERS, Isabelle. 2015. No tempo das catástrofes. São Paulo: Cosac Naify, 2015.

TOLEDO, Víctor M.; BARRERA-BASSOLS, Narciso. A memória biocultural. São Paulo: Expressão Popular, 2015.

TSING, Anna. Viver das ruínas: paisagens multiespécies no antropoceno. Brasília: IEB Mil Folhas, 2019.

VIANNA, Lucila Pinsard. 2008. De invisíveis a protagonistas: populações tradicionais e unidades de conservação. São Paulo: Annablume, 2008.

WEST, Paige; IGOE, James; BROCKINGTON, Dan. 2006. Parks and peoples: the social impact of protected areas. Annual Review of Anthropology, n. 35, p. 251-277, 2006.

WEST, Paige; BROCKINGTON, Dan. An anthropological perspective on some unexpected consequences of protected areas. Conservation biology, v. 20, n. 3, p. 609-616, 2006. 